\title{
Rosana Pinheiro-Machado Mañana será más grande. Lo que pasó en Brasil y las posibles rutas de fuga para la actual crisis.
}

Editorial Planeta, São Paulo, Brasil, 2019.

Gastón Passi Livacic*

El presente libro de la antropóloga brasileña, Rosana PinheiroMachado**, versa sobre parte importante de las últimas transformaciones sociales en Brasil, particularmente mediante la comprensión de los denominados nuevos movimientos sociales. El eje nodal de la investigación es examinar los cambios a partir de las masivas protestas sociales que se originaron en el gigante sudamericano en junio de 2013. A diferencia de la mayoría de los estudios sobre la crisis democrática brasileña (vertiente institucionalista - golpe de Estado, otros), se comprende la emergencia de lo colectivo a través de dos grandes ejes orientadores, por un lado, en la alteración de lo cotidiano y sus implicancias en el sistema político y en segundo término, en la asunción de nuevos tipos de movimientos sociales a nivel sistémico.

Además de la vertiente novedosa para analizar la fractura política y social en la democracia brasileña, fundamentalmente a través del estudio de campo en distintas dimensiones sociales que irrumpen en la

Cientista político, Magíster en Ciencias Sociales. Universidad Federal de Santa Maria, Rio Grande do Sul, Brasil. E-mail: gaston_pl86@hotmail.com

** Es la autora del libro Amanhã vai ser maior, o que aconteceu com o Brasil e possíveis rotas de fuga para a crise atual, Editorial Planeta, 2019; es cientista social y antropóloga; como intelectual pública, sus columnas se viralizaron en diversas oportunidades y pautearon el debate nacional e internacional, como ocurrió en la época de los rolezinhos, en la huelga de los camioneros y en la elección de Jair Bolsonaro. Actualmente, es profesora de Desarrollo Internacional en la Universidad de Bath (Reino Unido) y en Fellow, escuela de enseñanza superior del Reino Unido. En Brasil, enseña en el programa de posgrado en Ciencias Sociales en la Universidad Federal de Santa Maria, UFSM, y además es columnista de The Intercept Brasil. 
nueva realidad nacional, otro elemento interesante de la investigación, aunque de forma limitada en su explicación, es referente a la causalidad de cambios sistémicos en la economía global y su incidencia en la articulación de un nuevo tipo de movimientos sociales. La producción académica de Rosana Pinheiro-Machado se construye, así, en dos grandes áreas temáticas: primeramente, analizando las mudanzas económicas en la esfera internacional y su relación con la gestación de nuevas formas de expresión social —nuevos movimientos sociales-, entendido como expresiones colectivas en diferentes territorios pero conectados en causas comunes, es decir, permeados por estructuras que repercuten de manera similar en los diferentes espacios políticos que habitan en el mundo globalizado. En una segunda etapa del libro, la más extensa y detallada, la autora aborda de forma cronológica la crisis brasileña, desde las protestas de junio de 2013 hasta la asunción de Jair Bolsonaro como presidente de la República de Brasil el primero de enero de 2019.

Las fisuras sociales del siglo XXI se articulan y contraponen a los movimientos sociales clásicos a partir del tiempo histórico que se configuran, así como de las nuevas tendencias o perspectivas que dominan lo que se podría entender en el libro como una etapa de la globalización. Esas transformaciones emanan de la crisis sub-prime de 2008, originaria de Estados Unidos, pero con un rápido impacto a nivel mundial. Las implicancias de la crisis, en términos económicos y políticos, de acuerdo con la autora, son esenciales para entender la gestación de los nuevos movimientos sociales. La globalización, mediante sus múltiples formas de interacción mundial, ha conllevado a un nivel de instantaneidad inusitado en relación a la integración de los territorios nacionales que la componen frente a esa marcha más rápida; las repercusiones del mercado financiero se recienten, de manera positiva o negativa, a escala planetaria derivada de sus diversas ramificaciones. Entre las consecuencias adversas en el poder del mercado financiero internacional, de acuerdo con Rosana Pinheiro-Machado, se alude a las constantes presiones que ejerce el modelo económico dominante —neoliberalismo-, en los estados nacionales así como en los cuerpos que gobierna.

La repercusión económica, política y social en una escala planetaria es el marco teórico para indicar nuevas formas de orientación polí- 
tica, en consecuencia, una serie de alteraciones al orden establecido y, de lo anterior, emergiendo una variada cantidad de expresiones sociales con petitorios similares que perturban, en diversos grados y formas, la cotidianidad vigente. Entre los cambios en curso, la autora los define como nuevas formas de polarización, es decir, nuevas formas de sentir, observar e integrarse en la vida social; fenómenos que se traspasan y tensionan a los sistemas políticos integrados a la globalización, es decir, "el colapso influyó en ocupaciones y protestas en todo el mundo" (Pinheiro-Machado, 2019, p. 18).

De un lado del espectro, referido a las transformaciones estructurales, surge lo que es denominado primavera global de otro lado de la vereda ideológica: irrumpen formas contestarias a las orientaciones colectivas del siglo XXI, básicamente, respuestas de carácter fascista y nacionalista a los efectos colaterales de la nueva etapa de la globalización. En esa vía teórica, ¿Cuáles son las lógicas que cambian las dinámicas políticas, económicas y sociales del mundo? Siguiendo los ejes analíticos de la autora, la nueva dimensión de la globalización, además de la instantaneidad inusual en sus efectos, establece y ordena tendencias encadenadas globalmente, tanto en lo económico como en lo político y en lo social. El mundo se convierte así en un hábitat cada vez más interconectado. Entre los elementos catalizadores de la expansión en la globalización se caracterizan vectores, tales como: ampliación en la calidad de internet y su alcance global, crisis económicas que atraviesan a todos los países, tránsito de capitales en grandes cantidades, tensiones asociadas a la expansión de la emigración, entre otros; al mismo tiempo, repercutiendo en crisis de representación de las democracias como regímenes de gobiernos. El modelo neoliberal, entendido como el sistema económico preponderante en el sistema internacional, es cada vez más es interpelado frente a las constantes crisis económicas y a las presiones que ejerce en términos políticos y sociales. Entre algunos de los elementos que configuran la realidad de los nuevos movimientos sociales es posible ilustrar parte de la explicación sistémica en el siguiente pasaje del libro Mañana será más grande: "La austeridad castiga día a día siendo la democracia secuestrada por las grandes corporaciones. Los Estados pasan a ser un brazo gestor del mercado financiero global, conscuentemente, contando con pocas posibilidades de actuar en el ámbito social" (Pinheiro-Machado, 2019, p. 20). 
La extrema derecha que surge del proceso en mención es catalogada como un tipo de organización política de indignación nacional frente a elementos considerados como nocivos para los intereses nacionales ponderados en riesgo frente a la globalización. Por consiguiente, las narrativas de orden nacionalista, el auge de los populismos, la exaltación de los símbolos nacionales van en dirección de colisionar con la nueva era de la globalización, fundamentalmente visualizada como la responsable de todos los males del mundo. Asimismo, el nuevo proceso de globalización trae consigo el surgimiento de los nuevos movimientos sociales. Sobre ese punto en particular, la autora hace una sucinta comparación entre los nuevos movimientos sociales y los movimientos sociales que podrían catalogarse como clásicos. Podría haber insistido de manera más profunda en esa comparación, sin embargo, la preocupación central se manifiesta en la intención de delinear las características comunes que pueden ser encontradas en las colectividades agregadas derivadas de los efectos adversos de la crisis económica de 2008.

De los movimientos sociales árabes, originados inicialmente en Túnez en 2011, con la denominada Primavera Árabe por la literatura de las ciencias sociales, emerge, según Rosana Pinheiro-Machado, lo que se podría catalogar de "primavera global" a una especie de marco que reúne a todos los nuevos movimientos sociales como fenómenos de un mismo tipo. Según la autora, "la tensión surgió en la zona del mercado y se extendió para la esfera política. Una fractura fue abierta en la estructura global produciendo un movimiento sísmico en el mundo para más allá de la economía" (Pinheiro-Machado, 2019, p. 17).

Entre las repercusiones en el campo social, las principales características de los nuevos movimientos sociales se configuran a partir de su lógica horizontal tanto en la organización, en la forma con que abordan el debate público, así como en la interpelación al poder establecido, afectando gravemente las democracias representativas. Otro de los elementos comunes es definido por la lógica del contagio cuyo epicentro es la Primavera Árabe, siendo su proliferación los distintos movimientos sociales que azotaron a Europa y al mundo. En Europa, la esencia de las manifestaciones emerge de la contestación a las políticas de austeridad postcrisis - todos los movimientos son entendidos como explosiones de problemas internos-, empero todos los nuevos 
movimientos sociales comparten una narrativa de orden política similar a favor de la justicia social y contrarios a los abusos de poder de las estructuras dominantes, principalmente de lo denominado como globalización corporativa. Sobre este punto, en particular, la autora hace referencia a que "habitantes de cada país se están reivindicado contra el capital financiero global, que solamente actúa para su propia reproducción" (Pinheiro-Machado, 2019, p. 21).

Toda esa clasificación teórica incentiva a la autora a examinar las transformaciones que evidencia Brasil, comparando las protestas del año previo a la organización Copa del Mundo de 2014 (manifestaciones conocidas en el mundo como El Gigante Despertó) con la Primavera Global. Uno de los ejes centrales de la antropóloga brasileña es comprender la energía vital que está por detrás de las masivas convocatorias en el gigante sudamericano. Frente a aquello es posible observar las siguientes interrogantes que intentan ser explicadas en el transcurso del libro: ¿Qué está aconteciendo en Brasil? ¿Por qué la población se siente frente a un tren desgobernado? ¿Las Jornadas de Junio son parte de la primavera global?, entre otras.

La elección de Jair Bolsonaro es considerada como el colapso del sistema político brasileño, particularmente de la polarización dominante desde el retorno a la democracia hasta las Jornadas de Junio de 2013 en adelante, sin embargo, la estructura del libro va más allá de la estructura institucional para comprender la fractura del sistema político brasileño. Su punto de análisis parte "por todo aquello que acontece fuera del radar institucional" (Pinheiro-Machado, 2019, p. 12). Para tales efectos, es decir, para significar los valores fuera de los parámetros tradicionales en la dimensión institucional, la autora organiza los capítulos del libro en orden cronológico, relatando el ciclo de insurgencias desde junio de 2013 hasta la asunción de la extrema derecha al poder.

Las políticas de integración esgrimidas durante la era petista generaron un cambio de paradigma que escapa la lógica binaria de derecha-izquierda, sobrepasando también a los mecanismos de representación. En Brasil, esa transformación es analizada mediante la energía vital de las explosiones sociales que emergieron en el último tiempo, como los "rolezinhos", protestas de camioneros, entre otros. Según Rosana Pinheiro-Machado, los movimientos no encontraron respuesta institucional, por varias razones: “A) Contradicciones del Lulismo; B) 
Los Hijos Rebeldes, C) Construcción de un ciclo de Esperanza Precario; D) Los Huérfanos de la Gobernabilidad, E) En el alineamiento de las Elites" (Pinheiro-Machado, 2019, pp. 29-32).

Sobre las categorías analíticas anteriores, estas se refieren a las lógicas internas, específicamente a las contradicciones de lulismo - particularmente al tránsito de integración a la estructura social de sujetos excluidos de participar activamente en la economía - de ingresar a las universidades, es decir, los puntos A y B hacen mención a las bolsas famílias, bolsas universitárias además de los esfuerzos de cimentar una ruta de derechos sociales. Parte de los manifestantes eran integrantes de esos grupos, sin embargo, siendo negados por el partido de los trabajadores al ser rotulados a todos los participantes de las protestas de junio de 2013 como fascistas. Si bien el ciclo de gobiernos del partido de los trabajadores fue un período de esperanza, esa ilusión es representada como sectorial y al mismo tiempo no abordando con la misma voluntad política la ampliación en derechos en otras áreas. Existe un grupo de apoyo social que rápidamente huye de la filiación, simpatía, partidaria derivada de los acuerdos del oficialismo con los partidos del establishment en pro de la gobernabilidad, fomentando, además, una gradual distancia del partido con el movimiento de base. Finalmente, los cambios estructurales, el mal manejo en la nueva estrategia de desarrollo implementado en el gobierno de Dilma, además de los casos de corrupción lava-jato fomentaron un ciclo de movilizaciones sin precedentes en país. Frente a esa coyuntura, "el poder sobre el cual Brasil se estructuró por cinco siglos estaba siendo mínimamente amenazado, eso ya era considerado demasiado. Las elites comenzaron a salir del armario en Junio del 2013" (Pinheiro-Machado, 2019, p. 32).

Esas son las causas mediantes las cuales el partido de los trabajadores pierde la mayoría en el sistema político. La tesis fundamental de la autora descansa en que la intelectualidad del partido no supo interpretar las protestas como un ciclo de insurrecciones en una escala global, lo que ella califica de primavera global. Por ende, las protestas son entendidas como un ciclo que escapa a la polarización clásica del siglo XX entre derechas e izquierdas. En ese nuevo escenario, el partido de los trabajadores no supo surfear en la onda de protestas; mientras tanto, la derecha, esa que se sintió mínimamente amenazada en la era petista, organiza políticamente la coyuntura a través de una guerra 
contra la corrupción, contra los petitorios de los movimientos sociales asociados o rotulados por ellos hacia la izquierda, ganando así territorio simbólico contra tales elementos promulgando, por ejemplo, en el período post-impeachment, una serie de medidas contra el legado del partido de los trabajadores. Entre tales pautas resalta "la escuela sin partido", así como una narrativa que parece dominante, con eslóganes tales como: "mi bandera jamás será roja" o "anda a vivir en Cuba", que tomaron una posición central en el debate político brasileño.

¿Es una batalla cultural ganada por la extrema derecha? Esa interrogante atraviesa todo el libro. En líneas generales, se puede resumir mediante la siguiente citación: "una mirada más generosa sobre Junio del 2013 requiere entender el fenómeno como Jornadas, como un proceso que no comenzó y ni terminó en un día" (Pinheiro-Machado, 2019, p. 33). En esa vía de interpretación, las reivindicaciones son proyectadas como pautas integralmente antiautoritarias, por ende, contrarias al aumento unilateral de la locomoción pública, posteriormente al costo de la vida en general, entre ellos, de la bencina (aumento asociado por el colectivo a los casos de corrupción de Petrobras), asimismo, impugnando los exagerados costos en la infraestructura del mundial y rechazando la represión estatal en el diseño de las ciudades para la Copa. Sobre el último punto, la expulsión de una comunidad indígena en las inmediaciones del estadio Maracaná, así como la criminalización a la expresión social fueron fenómenos interpretados por los brasileños como la captura del Estado por intereses privados en detrimento de lo público.

En ese sentido, la victoria de Bolsonaro es parte del proceso institucional de la mejor lectura de la extrema derecha de las nuevas pautas de acción que trae la nueva fase de la globalización, la exaltación de lo nacional, pero en ningún momento se podría catalogar como el triunfo cultural de las Jornadas de Junio. Las pautas de las Jornadas de Junio son antiautoritarias por esencia, demandando bienes colectivos globales como hospitales públicos de calidad (padrón FIFA), es decir, son pautas que aluden al fin de la corrupción. En consecuencia, se busca sobreponer el bienestar social por intereses corporativos; es la etapa de una nueva cultura social en emergencia en Brasil.

El libro de Rosana Pinheiro-Machado es una obra recomendada que imbrica de manera interesante y dinámica los nuevos movimien- 
tos sociales como un fenómeno de orden sistémico con las experiencias colectivas locales, en este caso en particular, detallando el ciclo de protestas que se evidencian en Brasil desde las Jornada de Junio de 2013 hasta la fecha. La relación entre la primavera global y los estallidos locales, así como los cambios sistémicos, son una óptica analítica que gana sistematicidad, empero, existen ciertas variables que requieren una mayor profundización: 1) Teorizar con mayor cobertura la construcción de lo que se comprende en el libro como una nueva era de la globalización y su incidencia sistémica, 2) comparar los movimientos sociales clásicos con los nuevos movimientos sociales y 3) profundizar en la caracterización de los nuevos movimientos sociales como fenómenos de una misma especie. Tales puntos permitirían entender de mejor forma la relación sistémica en los nuevos movimientos sociales de las lógicas internas, al mismo tiempo que sus características propias así como los puntos de encuentros. La energía vital que se moviliza en Brasil, en varios pasajes del libro, parece tener una perspectiva más local que sistémica, aunque ilustrada de manera clara y didáctica, sin duda; es una obra fundamental para seguir profundizando sobre los puntos esbozados, asimismo, para tener una mirada minuciosa de los cambios sociales latentes en Brasil. Finalmente, se postula que la energía en movimiento no ha sido canalizada en algún proyecto político que aglomere la esencia de los últimos movimientos sociales en una narrativa común en Brasil. Por tales motivos, se configura la tesis que comprende a las protestas de un mañana próximo como más grandes que las actuales. 